Review article

\title{
Identification and applications of neuroactive silk proteins: a narrative review
}

\author{
Ahad Banagozar Mohammadi 1,2, Saeed Sadigh-Eteghad ${ }^{2}$, Mohammadali Torbati ${ }^{3}$, \\ Seyyed Mohammad Bagher Fazljou ${ }^{1}$, Seyed Mehdi Vatandoust ${ }^{2}$, Samad EJ Golzari ${ }^{4,5}$, \\ Fereshteh Farajdokht ${ }^{2}$, Javad Mahmoudi ${ }^{2}$ * \\ ${ }^{1}$ Tabriz University of Medical Sciences, Faculty of Traditional Medicine, Department of Traditional Medicine, Tabriz, Iran \\ 2 Tabriz University of Medical Sciences, Neurosciences Research Center (NSRC), Tabriz, Iran \\ ${ }^{3}$ Tabriz University of Medical Sciences, Faculty of Nutrition, Department of Food Science and Technology, Tabriz, Iran \\ ${ }^{4}$ Tabriz University of Medical Sciences, Research Center for Evidence Based Medicine, Tabriz, Iran \\ ${ }^{5}$ Tabriz University of Medical Sciences, Health Management and Safety Promotion Research Institute, Road Traffic Injury Research Center, Tabriz, Iran
}

\section{Abstract}

In traditional medicine, natural silk is regarded as a cognitive enhancer and a cure for ameliorating the symptoms of heart disease, atherosclerosis, and metabolic disorders. In this review, general characteristics of both silk proteins, fibroin and sericin, extracted from silkworm Bombyx mori and their potential use in the neuronal disorders was discussed. Evidence shows that silk proteins exhibit neuroprotective effects in models of neurotoxicity. The antioxidant, neuroprotective, and acetylcholinesterase inhibitory mechanisms of silk proteins could prove promising in the treatment of neurodegenerative diseases. Owing to their excellent neurocompatibility and physicochemical properties, silk proteins have been used as scaffolds and drug delivery materials in the neuronal tissue engineering. These data support the potential of silk proteins as an effective complementary agent for central and peripheral neurological disorders.
\end{abstract}

Keywords: Fibroin; Neuroprotection; Sericin; Silk proteins

\section{Highlights:}

- Silk proteins may hold promising alternatives for the treatment of neurodegenerative diseases.

- Silk proteins diminish oxidative stress damage and enhance enzymatic antioxidant activity.

- Silk proteins have potential to be used in neuroregeneration.

\section{Introduction}

Silkworm, the larva or caterpillar of the domesticated silkmoth (Bombyx mori), commercially viable in the production of silk. Silkworms depend upon the leaves of the mulberry trees as food (Ahsan et al., 2018). Excellent physical properties of silk, such as lightweight, high mechanical strength, and flexibility, make it appropriate to produce new biomaterials with application in tissue repair and drug delivery (Florczak et al., 2014). Silk has been commonly used for centuries as a suture material for wound treatment. Besides the vast application of silk in the textile industry, it has been widely used in traditional medicine as a home-made remedy for improving a broad range of health-related complications, particularly in the cardiac and nervous system (Nazmi et al., 2011). In Unani medicine, the silk is known as Abresham muqriz (muqriz means cut). Its cocoons are broadly used as an ingredient for several Unani formulations including Khamira Abresham Hakeem
Arshad Wala (KAHAW), Khameer-E-Abresham Sada, and Khameere Abresham Ood Mastagi Wala (Ahsan et al., 2018). Avicenna introduced silk (Abresham) as a strong exhilarant, cardiotonic, and cardioprotective substance (Hameed, 1983; Sina, 1995). Further, the Food and Drug Administration (FDA) has approved silk medical devices for sutures and as a support structure during reconstructive surgery. Also, silk has recently gained attention in developing degradable electronic and photonic implantable medical devices (Huang et al., 2018; Preda et al., 2013). Silk proteins have antidiabetic, anti-hypercholesterolemic and metabolic modulator, cardioprotective, anti-tumor, antioxidant, anti-bacterial, wound healing, cell proliferation, UV protection, and cryopreservation (Ahsan et al., 2018; Padamwar and Pawar, 2004).

The silkworm cocoon is a single continuous and lustrous raw silk strand with approximately $700-1500 \mathrm{~m}$ length, which protects silkworms against invasion by natural predators and environmental damage enhancing survival chance of silkworm (Zhang et al., 2013). Cocoon silk shows structural stability ow-

\footnotetext{
* Author for correspondence: Fereshteh Farajdokht and Javad Mahmoudi, Tabriz University of Medical Sciences, Neurosciences Research Center (NSRC), Golgasht Street, Azadi Avenue, 5166614756 Tabriz, Iran; e-mail: farajdokhtf@tbzmed.ac.ir; mahmoudij@tbzmed.ac.ir; mahmoudi2044@yahoo.com; http://doi.org/10.32725/jab.2019.012

Submitted: 2019-03-13 • Accepted: 2019-06-20 • Prepublished online: 2019-08-14

J Appl Biomed 17/3: 147-156 • EISSN 1214-0287 • ISSN 1214-021X

(c) 2019 The Authors. Published by University of South Bohemia in České Budějovice, Faculty of Health and Social Sciences.

This is an open access article under the CC BY-NC-ND license.
} 
ing to the abundance of anti-protease proteins that improve the silk resistance (Zhang et al., 2017).

In spite of the extensive use of silk proteins, there is no comprehensive review regarding its neurological activities and applications. In this review, firstly, we will discuss the features of silk proteins, including fibroin and sericin, then their applications in the treatment of different neurological disorders and their possible mechanisms of action.

\section{Silk proteins}

The silk is a natural fiber composed of two essential proteins, mainly fibroin and sericin. Other minor natural impurities of raw silk include carbohydrate, inorganic salts, wax, and pigment (Mondal, 2007). Silk fibroin, the structural center of the silk, is double strand insoluble protein, linked by disulfide bonds, has a semi-crystalline structure that consists $70 \%$ of the cocoon shell of $B$. mori. The fibroin shell constitutes the core of silk and is covered by successive sticky layers of sericin (Fig. 1). The structure of fibroin mainly consists of the repeated amino acid sequence (Gly-Ser-Gly-Ala-Gly-Ala) $n$ that form antiparallel beta sheets (Qi et al., 2017). The high glycine content $(45 \%)$ contributes to the unique structure of silk and its resistant to breaking.

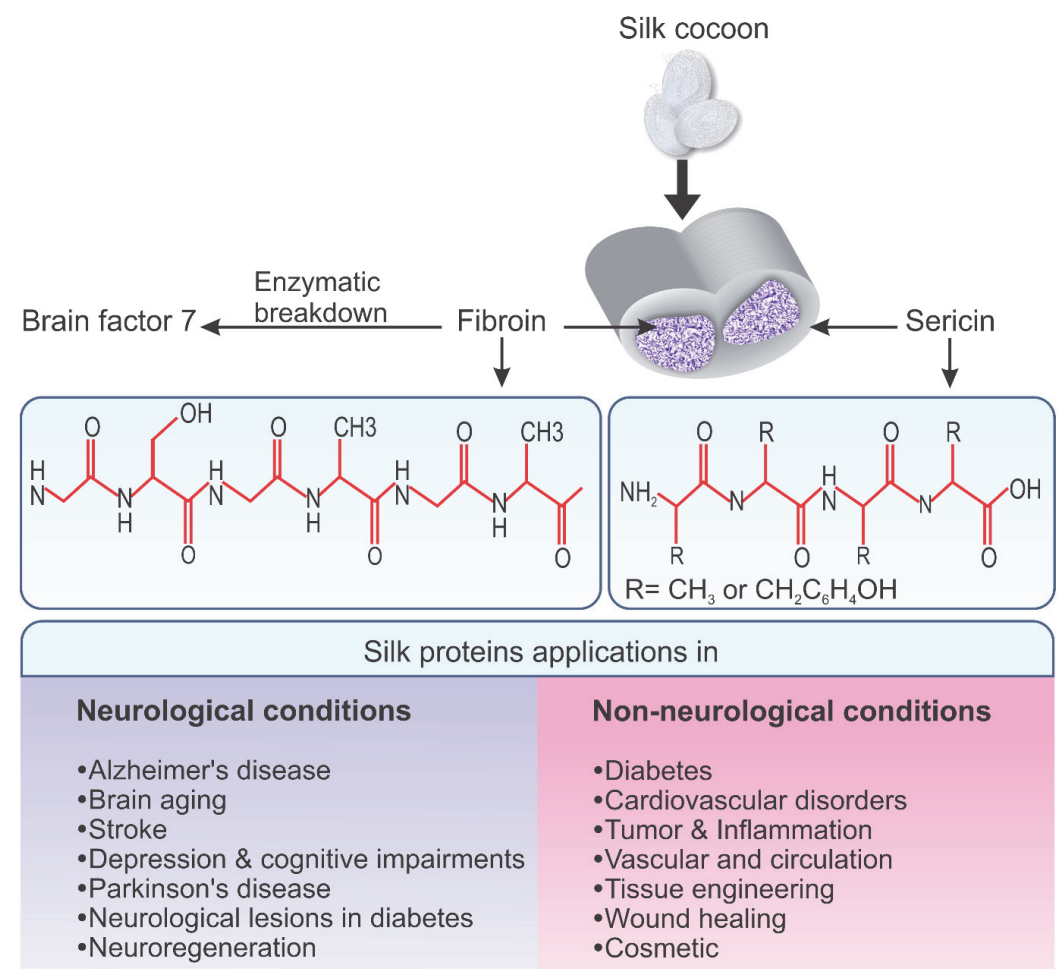

Fig. 1. A schematic theme of the review

Silk fibroin is biologically degraded by proteolytic enzymes such as chymotrypsin, actinase, and carboxylase. Fibroin is extracted from the silkworm cocoon by removal of sericin mainly by a thermo-chemical procedure known as degumming. Most of the sericin is removed in the course of raw silk production, increasing the softness, luster, smoothness, and whiteness of silk fibers (Gupta et al., 2013). Fibroin filament is composed of both amorphous and crystalline domains. Brain factor-7 (BF-7), a natural peptide extracted from B. mori, is prepared by enzymatic degradation of silk fibroin protein, in which raw silk is exposed to filtration and purification processes and proteolysis. Briefly, silk cocoon is washed, and the outer sericin protein is removed. To open up protein sheet, the remaining fibroin is heated in the presence of calcium chloride so protease enzymes can digest fibroin protein into smaller proteins (Chae et al., 2004; Kim et al., 2009). BF-7 is a natural brain-nourishing peptide extract in silk with a molecular weight range of 500-5000 daltons. BF-7 is a protein hydrosylate with a $\beta$-sheet structure rich in glycine and alanine, which are crucial amino acids for proper neurotransmitter function and cellular energy production. It has good solubility in water and other aque- ous solutions. Due to its small size, BF- 7 can readily cross the blood-brain barrier, where it can affect the brain cell and promote cognitive function (Kang et al., 2018).

Sericin $(20-310 \mathrm{kDa})$ is a hydrophilic and globular glycoprotein that constitutes $20-30 \%$ of total cocoon weight. Indeed, sericin is a glue-like protein that joins two fibroin filaments to form silk yarn (Mondal, 2007). It contains 18 amino acids, 8 of them are essential for human, and a high content of hydrophilic amino acids, namely serine (30\%) and glycine. Sericin has abundant polar side chains made of hydroxyl, carboxyl, and amino groups. Sericin exists mainly in a random coil and to a lesser extent in a $\beta$-sheet structure and is insoluble in cold water (Padamwar and Pawar, 2004). Its organic composition include $46.5 \%$ carbon, $31 \%$ oxygen, $16.5 \%$ nitrogen, and $6 \%$ hydrogen. The water solubility of sericin decreases by transforming from random coil to $\beta$-sheet structure. Isolation methods of sericin from silk thread affect its solubility, molecular weight, and gelling properties. Formerly, silk sericin was considered as a waste material of silk industry, but recent studies have proven its effectiveness in the pharmacological, biotechnological, and cosmetic applications such as wound 
healing, antiwrinkle and antiaging (Mondal, 2007). Sericin is classified into three fractions upon their solubility and position within the layer of the cocoon, including sericin $A, B$, and $C$. These fractions build up the layers found on the silk fibroin. Sericin A composed the outer layer and is more soluble in warm water. Sericin B is the intermediate layer, and sericin $C$ is the innermost layer, or the closest to the fibroin (Larin, 1951).

Several methods are used for extraction of silk sericin such as hot water, gel electrophoresis, enzymes (trypsin, alkaline protease or alkylase), spray-drying method, and aqueous urea. The physicochemical properties of sericin rely on the technique of sericin isolation (Padamwar and Pawar, 2004). Silk proteins can be processed in aqueous environments into various material formats, including films, sponges, electrospun mats, and hydrogels (Cao and Zhang, 2016; Lamboni et al., 2015). In contrast to earlier studies (Celedón et al., 2001; Zaoming et al., 1996), recent studies showed that soluble sericin is immunologically inert and safe (Chlapanidas et al., 2013; Panilaitis et al., 2003; Terada et al., 2005), proposing it a promising candidate for various biomedical applications. Given its unique properties such as antioxidant, antidiabetic, antihyperlipidemic, anti-inflammatory, skin moisturizing, healing, antibacterial, antimicrobial protection, and antitumour (Table 1) (Aramwit et al., 2012; Kato et al., 1998b; Kunz et al., 2016), sericin has been widely used in biomedical, tissue engineering, regenerative medicine, and pharmaceutical and food industries. Sericin by cross-linking and mixing with other polymers can form a desirable scaffold with application in the pharmaceutical and cosmetic preparations (Aramwit et al., 2012).

Table 1. Summary of important non-neurological properties of silk proteins

\begin{tabular}{|c|c|c|c|}
\hline Effects & Description & Protein type & References \\
\hline $\begin{array}{l}\text { Antidiabetic } \\
\text { effects }\end{array}$ & $\begin{array}{c}\text { No nutritional effect } \\
\text { Reduce blood glucose and glycosylated hemoglobin (HbA1c) levels, improve } \\
\text { glucose tolerance and increase insulin levels } \\
\text { Increase pancreatic } \beta \text { cell mass } \\
\text { Increase serum levels of the insulin-like growth factor-1 (IGF-1), growth } \\
\text { hormone (GH) receptor, and adiponectin levels } \\
\text { Decrease leptin and resistin levels } \\
\text { Reduce the body fat content, triglyceride, and total cholesterol levels, } \\
\text { atherogenic index, free unsaturated fats, phospholipids, very low-density } \\
\text { lipoproteins (VLDL), low-density lipoprotein (LDL), and free fatty acid level }\end{array}$ & $\begin{array}{l}\text { Fibroin and } \\
\text { Sericin }\end{array}$ & $\begin{array}{l}\text { Chen et al., } 2013 \\
\text { Do et al., } 2012 \\
\text { Okazaki et al., } 2010 \\
\text { Rattana et al., } 2017 \\
\text { Seo et al., } 2011\end{array}$ \\
\hline Cardioprotection & $\begin{array}{l}\text { Protect against atherosclerosis } \\
\text { Protect against doxorubicin (Dox)-induced cardiotoxicity } \\
\text { Prevent isoprenaline-induced myocardial damage and hypertrophy } \\
\text { Improve cardiac functional recovery after myocardial infarction }\end{array}$ & Sericin & $\begin{array}{l}\text { Ali and Arumugam, } 2011 \\
\text { Goyal et al., } 2010 \\
\text { Khan et al., } 2014 \\
\text { Srivastav et al., } 2013\end{array}$ \\
\hline $\begin{array}{l}\text { Antitumor } \\
\text { and anti- } \\
\text { inflammatory } \\
\text { effects }\end{array}$ & $\begin{array}{l}\text { Decrease cell proliferation rate and oncogenes expression } \\
\text { Induce apoptosis of tumor cells by triggering the activity of pro-apoptotic } \\
\text { proteins } \\
\text { Very low immunogenicity, reduce the release of interferon gamma (IFN- } \gamma \text { ), } \\
\text { tumor necrosis factor-alpha (TNF- } \alpha \text { ), and interleukin (IL)-1 } \beta \\
\text { Reduce percentage of CD8a and CD80 cells, and increase activity of natural killer } \\
\text { (NK) cells }\end{array}$ & $\begin{array}{l}\text { Sericin and } \\
\text { Fibroin }\end{array}$ & $\begin{array}{c}\text { Aramwit et al., } 2009 \\
\text { Chlapanidas et al., } 2013 \\
\text { Keawkorn et al., 2012, } 2013 \\
\text { Promphet et al., 2014 } \\
\text { Sasaki et al., 2000 } \\
\text { Zhaorigetu et al., } 2001\end{array}$ \\
\hline $\begin{array}{l}\text { Vascular and } \\
\text { circulation } \\
\text { effects }\end{array}$ & $\begin{array}{l}\text { Anticoagulant } \\
\text { Vasodilation and relaxation of the smooth muscle of the artery wall }\end{array}$ & Sericin & $\begin{array}{l}\text { Onsa-Ard et al., } 2013 \\
\text { Tamada et al., } 2004\end{array}$ \\
\hline $\begin{array}{l}\text { Tissue } \\
\text { engineering }\end{array}$ & $\begin{array}{l}\text { Act as chief ingredient for bioimaging, drug delivery, tissue regeneration, and } \\
\text { scaffold for tissue regeneration }\end{array}$ & $\begin{array}{l}\text { Sericin and } \\
\text { Fibroin }\end{array}$ & $\begin{array}{l}\text { Aramwit et al., } 2015 \\
\text { Kurland et al., } 2014 \\
\text { Panico et al., } 2018 \\
\text { Xiong et al., } 2017 \\
\text { Zhang et al., } 2015 \\
\end{array}$ \\
\hline Wound healing & $\begin{array}{l}\text { Improve skin repair and collagen production } \\
\text { Increase proliferation and migration of keratinocytes and fibroblasts into the } \\
\text { injured area }\end{array}$ & Sericin & $\begin{array}{l}\text { Aramwit and Sangcakul, } 2007 \\
\text { Aramwit et al., } 2010 \mathrm{~b} \\
\text { Liang et al., } 2007\end{array}$ \\
\hline Cosmetic effects & $\begin{array}{c}\text { Increase hydration and elasticity of the skin, antiaging and antiwrinkle, and skin } \\
\text { conditioner, cleaning with less irritation } \\
\text { Protect surface hair from damage } \\
\text { Protect nail from drying and fragility }\end{array}$ & Sericin & $\begin{array}{l}\text { Ahsan et al., } 2018 \\
\text { Oshika and Naito, } 1998 \\
\text { Wong et al., } 2014\end{array}$ \\
\hline
\end{tabular}

\section{Application of silk proteins in neurological disorders}

Alzheimer's disease

Studies on neurodegenerative disorders, such as aging and Alzheimer's disease (AD), appreciated the cognitive enhancing properties of sericin. As the most common type of dementia, the $\mathrm{AD}$ is characterized by the formation of neurofibrillary tangles and amyloid plaques, brain atrophy, and loss of neurons resulting in memory impairments (Arborelius et al.,
1999). Cognitive impairments in AD are generally associated with reduced synthesis of the acetylcholine (ACh) and overproduction of reactive oxygen species (ROS) in the cerebral cognitive-related structures, such as the hippocampus and cerebral cortex. Studies in AD have supported the importance of the antioxidants and acetylcholinesterase (AChE) inhibitor regimens for lessening of $\mathrm{AD}$-related cognitive symptoms (Peera and Yellamma, 2015). 
Pro-cognitive effect of BF-7 has been reported in both animal and human studies. Chae et al. (2004) have shown that BF-7 protects against amyloid-beta $(\mathrm{A} \beta)$-induced apoptosis through the attenuation of ROS overproduction and inhibition of caspase- 3 activity in the human neuronal cell. Pretreatment of neuroblastoma cells with milk fortified with fibroin BF-7 for seven days decreased $A \beta$ neurotoxicity and increased cell survival rate (Choi et al., 2008). BF-7 was also shown to protect the human neuronal cell against scopolamine-induced neurotoxicity in vitro, and attenuate memory impairments induced by scopolamine in vivo (Iborra et al., 2004). Moreover, BF-7 (5 and $10 \mathrm{mg} / \mathrm{kg} /$ day for two weeks) increased ACh concentrations in the brain of rats treated with $\mathrm{A} \beta$ (Kim et al., 2005). Fibroin BF-7 has also been demonstrated to improve learning and memory impairments in $\mathrm{A} \beta$ induced $\mathrm{AD}$ model and to attenuate $\mathrm{A} \beta$-induced apoptosis through decreasing intracellular calcium levels and ROS production, as well as inhibition of mitochondrial dysfunction and caspase activity (Lee et al., 2007).

Ethylcholine mustard aziridinium ion (AF64A) is a presynaptic cholinergic neurotoxin that causes alterations in mRNA expression and activity of choline acetyltransferase (ChAT), a necessary enzyme for ACh synthesis, resulting in a decrease of ACh release leading to memory and learning deficits (Walsh and Opello, 1994). Cha et al. (2017) have demonstrated that silk peptides treatment for five weeks in AT64A-induced AD model animals enhanced the expression of ChAT mRNA and increased $\mathrm{ACh}$ in the cerebrospinal fluid associated with improvement of cognitive deficits and suppression of hippocampal astrocytic activation.

\section{Brain aging}

D-galactose can induce many features of brain aging and has been widely applied to study the mechanisms of brain aging in rodents (Sadigh-Eteghad et al., 2017). Several studies have demonstrated that cognitive dysfunction, along with aging arises from oxidative stress and mitochondrial dysfunction. Research shows that sericin can reverse the memory impairments in D-galactose induced AD model through increasing ACh levels, inhibition of AChE activity, scavenging ROS, and the improvement of the antioxidant defense system in the hippocampus and cerebral cortex (Yellamma, 2014). It was reported that pretreatment (for five weeks prior to D-galactose injection) with two enzymatically modified silk peptides in a D-galactose induced aging model showed that silk peptides effectively inhibit AChE activity in the brain while enhancing the expression of the ChAT in vitro. Moreover, these silk peptides exhibited cognition-improving activities in both learning and memory tasks accompanied by the increase of $\mathrm{ACh}$ release and decreased the number of hippocampal activated astrocytes (Park et al., 2011). Moreover, two months administration of silk sericin ( $200 \mathrm{mg} / \mathrm{kg} /$ day) has been shown to improve learning and memory impairments in the Morris water maze in D-galactose-induced AD model in rats (Peera and Yellamma, 2013). Peera and Yellamma (2015) also reported that silk sericin improved D-galactose induced memory impairment through inhibition AChE activity and ultimately increasing ACh contents in the hippocampus and cerebral cortex, suggesting neuroprotective effects of silk protein on the cholinergic system. Another study showed positive effects of silk sericin on cognitive functions in D-galactose-induced AD model (Peera and Yellamma, 2016). Chen et al. (2011) have also demonstrated that sericin treatment improves learning and memory impairment induced by diabetes through attenuation of hippocampal nitric oxide (NO) contents and inhibition the nitric oxide synthase expression.

\section{Anxiety and depression}

Depression and anxiety are common psychiatric disorders worldwide. Preclinical and clinical evidence shows that neuroinflammation and oxidative stress in the structures involved in the regulation of mood and cognitive functions, hippocampus (HIP) and prefrontal cortex (PFC), play causative roles in the pathophysiology of these mood disorders (Banagozar Mohammadi et al., 2019; Haapakoski et al., 2015; Salehpour et al., 2019).

Recently, our group showed that sericin administration (100, 150, and $200 \mathrm{mg} / \mathrm{kg} /$ day, for 21 days) attenuated anxiety-and depressive-like behaviors induced by restraint stress accompanied by reduced serum corticosterone concentration in mice. Moreover, sericin could markedly diminish ROS and lipid peroxidation levels, restore mitochondrial membrane potential, and enhanced enzymatic antioxidant defense in the HIP and PFC. Furthermore, these results were associated with suppression of neuroinflammatory response and mitochondrial-dependent apoptosis in the HIP and PFC (Banagozar Mohammadi et al., 2019).

\section{Stroke}

Interruption of cerebral blood flow by a stroke can induce oxidative damage and neuroinflammation triggering brain dysfunction and cognitive impairments (Juurlink and Sweeney, 1997; Leker and Shohami, 2002). The protective effect of BF-7 on learning and memory deficits was also shown in the transient middle cerebral artery occlusion induced focal cerebral ischemia, which was associated with decreased size of infarcted areas and hippocampal neuronal cell death (Lee et al., 2005).

\section{Nootropic}

Chae et al. have reported that administration of BF-7 for one month improves learning and memory in healthy high school students (Chae et al., 2004). Clinical studies also showed that BF-7 improves short-term and long-term memories, cognitive flexibility, and attention in healthy school children (Kim et al., 2009; Kim et al., 2010a). A double-blind, placebo-controlled study reported that three weeks administration of BF-7 (200 and $400 \mathrm{mg}$ ) improved cognitive function in healthy adults in a dose-dependent manner (Lee et al., 2004). Silk fibroin BF-7 (400 mg/day for three weeks) was shown to enhance cognition through increasing glucose metabolism and blood supply to the brain structure involved in learning and memory including parahippocampal gyrus and medial temporal areas (Lee et al., 2004). Interestingly, a recent human study has found that three weeks administration of silk fibroin enzymatic hydrolysate $(0,280,400$, and $600 \mathrm{mg} /$ day $)$ dose-dependently improved verbal and visual memory and executive function with no adverse effects in healthy adults (Kang et al., 2018).

\section{Parkinson's disease}

Parkinson's disease (PD) is a progressive neurodegenerative disorder associated with progressive loss of dopaminergic neurons mainly in the substantia nigra, thereby in dopamine depletion, and the accumulation of $\alpha$-synuclein (Moore et al., 2005). L-3,4-dihydroxyphenylalanine (L-DOPA) is a dopamine precursor which has been used as a standard therapeutic for PD which reliefs movement impairments. However, long-term L-DOPA therapy can induce cytotoxicity by autoxidation to reactive species such as dopamine quinone, and overproduction of ROS and 6-hydroxydopamine (6-OHDA) (Asanuma et al., 2003). Tyrosinases are copper-containing enzymes that are involved in cancer and neurodegenerative diseases such as 
PD. Over-expression of tyrosinase induces cell death by triggering ROS production in neuroblastoma cells (Hasegawa et al., 2008). Evidence also shows that tyrosinase is involved in both the hydroxylation of tyrosine to L-DOPA and the subsequent oxidation of L-DOPA to dopamine quinone, and thereby exacerbates L-DOPA neurotoxicity (Asanuma et al., 2003; Greggio et al., 2005; Sánchez-Ferrer et al., 1995). Previous studies have reported that silk sericin has an antityrosinase activity (Aramwit et al., 2010a; Kato et al., 1998b). Moreover, silk peptides were shown to protect against 6-OHDA-induced apoptotic neuronal death (Kim et al., 2011a). Interestingly, Kim et al. (2011b) have demonstrated that silk amino acid improves motor impairments in 6-OHDA induced PD model through the preservation of the dopaminergic neurons against $6-O H D A-i n d u c e d$ neurotoxicity, and thus recovery of dopamine concentration.

Monoamine oxidases (MAO) are a family of enzymes that control the breakdown of monoamines such as dopamine, serotonin, and norepinephrine in the brain. MAO inhibitors prevent the removing of these neurotransmitter from the brain, which makes these brain chemicals more available. MAO-A inhibitors have been widely used in the treatment of depression and psychiatric disorder, and MAO-B inhibitors in the treatment of PD (Youdim and Riederer, 2004; Youdim et al., 2006). Interestingly, administration of silkworm extract $(20 \mathrm{mg} / \mathrm{kg}$ / day for 14 days) in mice was reported to inhibit MAO-A activity, a dopamine-degrading enzyme, in the whole brain, cerebral cortex, and substantia nigra and MAO-B in the cerebellum and substantia nigra (Kang et al., 2005). Another study has shown that silkworm extract attenuated N-methyl-4-phenyl-1,2,3,6-tetrahydropyridine (MPTP)-induced dopamine depletion in the substantia nigra accompanied by inhibition of the activity of MAO-B in the substantia nigra, cerebellum, and whole brain (Kang et al., 2010). Therefore, based on above, it seems that silk peptides could be a promising candidate for the improvement of PD symptoms.

\section{Neurological lesions in diabetes}

Diabetes is a metabolic disorder that is associated with impaired glucose tolerance, hyperglycemia, insulin resistance, and dyslipidemia ultimately initiating inflammation and oxidative stress in different tissues, particularly in the brain (Tangvarasittichai, 2015). A growing body of preclinical and clinical evidence linked diabetes to neurodegeneration disorders and cognitive impairment (Verdile et al., 2015). The hippocampus is known to be more prone to deleterious effects of the chronic hyperglycemia associated with diabetes. Indeed, chronic hyperglycemia associated with diabetes can result in apoptotic cell death of hippocampal neurons and abnormal volumetric changes in this structure, which ultimately lead to cognitive dysfunction (Chen et al., 2012; Mijnhout et al., 2006). On the other hand, agents with antidiabetic effects can protect the brain against diabetes-induced neurodegeneration and learning and memory impairments (Alagiakrishnan et al., 2013; El-Mir et al., 2008; Patrone et al., 2014). In this regard, previous studies have confirmed antidiabetic effects of silk proteins, evident by reducing glucose levels and $\mathrm{HbA1c}$, improving glucose tolerance and lipid profile, and increasing plasma insulin and adiponectin levels (Do et al., 2012; Jung et al., 2010; Kim et al., 2010b; Okazaki et al., 2010). Moreover, administration of sericin ( $2.4 \mathrm{~g} / \mathrm{kg} /$ day for 35 days) can also reduce hippocampal neuronal apoptosis through promoting Akt signaling pathway and inhibition of pro-apoptotic BAD protein and its mRNA expression in type 2 diabetic rats (Chen et al., 2012).
The growth hormone (GH)/insulin-like growth factor 1 (IGF-1) axis is implicated in the growth and development of the CNS. Moreover, hippocampal expression of IGF-1 contributes to neuroprotection, synaptic regeneration, myelin formation, and neuroregeneration following hippocampal injury (Shangguan and Shi, 2007). In diabetes owing to GH resistance and reduced IGF-1 levels and expression of GH receptor, GH/IGF-1 axis undergoes abnormal changes, which results in abnormal blood glucose levels and accordingly aggravate the disease progression and complications (Chiarelli et al., 2004; Kim et al., 2006). Given that IGF-1 has an anti-apoptotic effect, a decrease in IGF-1 expression in the diabetic brains may induce hippocampal neuronal apoptosis and cognitive impairments (Cardona-Gómez et al., 2001; Feldman et al., 2002; Wine et al., 2009). However, administration of sericin ( $2.4 \mathrm{~g} / \mathrm{kg} /$ day for 35 days) has been shown to attenuate hippocampal damage in diabetic rats through the improvement of the GH/IGF-1 axis (Chen et al., 2013). Furthermore, chronic administration of sericin has been demonstrated to decrease overexpression of heme oxygenase- 1 in the hippocampal CA1 subfield and cerebral cortex of diabetic rats (He et al., 2011). In addition, chronic silk sericin can decrease nitric oxide $\left(\mathrm{NO}^{-}\right)$ contents in the hippocampus of diabetic rats (Li et al., 2012). Sercin has also been reported to protect against diabetes-induced peripheral nerve injury, namely sciatic nerve, through increasing the expression of nerve growth factor and neurofilament protein expression, the primary marker identifying the function of synapses, in $\mathrm{L}_{4-6}$ spinal ganglion and anterior horn cells. Moreover, sericin ameliorates nerve tissue ischemia and hypoxia induced by vasoconstriction and inhibition of neurotransmitter release due to excessive neuropeptide $\mathrm{Y}$ in diabetic rats (Song et al., 2013; Zhao et al., 2012).

\section{Antioxidant potential}

Oxidative stress damage is caused by an imbalance between free radicals formation and detoxification capacity of cells (Fridovich, 1986; Halliwell and Gutteridge, 2015), resulting in DNA fragmentation, lipid peroxidation, and protein oxidation and thereby cell death (Maes et al., 2009a, b, 2011). Due to large amounts of polyunsaturated fatty acids, high oxygen demand, and limited antioxidant capacity, brain tissue is vulnerable to oxidative stress disrupting neurotransmission and neuronal functions (Cobley et al., 2018; Hulbert et al., 2007; Salim, 2017; Shichiri, 2014). Oxidative stress plays a causative role in the pathophysiology of common neurodegenerative diseases, especially in $\mathrm{PD}$ and $\mathrm{AD}$. Therefore, agents with the antioxidant property have been proposed for the prevention and treatment of neurodegenerative diseases (Kim et al., 2015).

The many medicinal advantages of silk can be attributed to its high antioxidant potential that confers protection against free radicals and oxidative damage. The mechanism underlying antioxidant property of sericin is related to its amino acid sequence and high content of hydroxyl amino acids such as serine and threonine, which enable chelating of free radicals and ROS. Importantly, the extraction methods may significantly affect the antioxidant activity of silk by affecting its molecular and functional properties such as contents of amino acids and polyphenol, molecular weight, and peptide length (Kumar and Mandal, 2017). In this regard, silk sericin extracted by urea displays the maximum antityrosinase activity, while alkali-degraded silk sericin cannot inhibit mushroom tyrosinase (Aramwit et al., 2010a). Kato et al. (1998a) have reported antioxidant effects of $0.3 \%$ sericin in the rat brain homogenate that was shown by decreased lipid peroxidation 
assessed by thiobarbituric acid reactive substances (TBARS). Moreover, sericin can increase enzymatic antioxidant activity (Dash et al., 2008; Kumar and Mandal, 2017). Sericin at dose $0.25 \mathrm{~g} / \mathrm{kg}$ has also been shown to protect the brain against oxidative stress induced by high-cholesterol diet in rats through attenuation the level of protein carbonylation and augmentation of the glutathione (GSH) levels in the brain tissue (Deori et al., 2016). Among the different mechanisms involved in $\mathrm{A} \beta$-induced neurotoxicity and apoptosis, ROS accumulation had received more attention (Hureau and Faller, 2009; Zawia et al., 2009). BF-7 was shown to attenuate $A \beta$-induced apoptosis through decreasing ROS generation in vitro (Chae et al., 2004; Kim et al., 2005). Moreover, silk sericin was reported to enhance the antioxidant activity of superoxide dismutase (SOD), catalase (CAT), and glutathione reductase (GR) enzymes in the cerebral cortex and hippocampus of D-galactose received rats (Peera and Yellamma, 2016). A recent in vitro study has found that silk fibroin hydrosylate protected SHSY5Y neuroblastoma cells and primary hippocampal neurons against $\mathrm{A} \beta_{25-35}$ induced apoptotic cell death and increased cell viability. The proposed mechanisms for its neuroprotection effects were attenuation of ROS accumulation, restoration of mitochondrial membrane potential, up-regulation of gene expression of SOD, inhibition the cleavage of pro-caspase 3 and the activation of MAPKs cascade, and suppression of protein phosphatase 2A (PP2A) phosphorylation and thereby inhibition of tau hyperphosphorylation (Xu et al., 2018). $\mathrm{NO}^{-}$is another cause for neuronal cell damages and its reaction with $\mathrm{O}_{2}$ forms peroxynitrite $\left(\mathrm{ONOO}^{-}\right)$that is highly reactive (Brieger et al., 2012). Li et al. (2012) have reported that silk sericin can decrease nitric oxide content in the hippocampus of diabetic rats. BF-7 $(10 \mu \mathrm{M})$ was shown to protect neuroblastoma cell against $\mathrm{FeSO}_{4}$-induced apoptosis through attenuation of ROS accumulation (Lee et al., 2004). Based on the above, it seems that silk proteins have potential applications in the treatment of $\mathrm{AD}$.

\section{Neuroregeneration}

The central or peripheral nerve injuries can lead to life-long disability, substantial work leave, and health care expenses. Therefore, nerve regeneration remains a major challenge in the clinic. Neural tissue engineering is a rapidly expanding research field aiming at nerve repair and regeneration (Gurgo et al., 2002; Ishihara et al., 2011).

Given their particular properties such as biocompatibility, low immunogenicity, slow degradation, flexibility, optimal mechanical strength, compatibility with sterilization methods, and FDA approval, silk proteins exhibit attractive potential applications in the neural tissue engineering and drug delivery (Hopkins et al., 2013; Li et al., 2013). Wang et al. (2015) used pure sericin hydrogel for ischemic neuronal tissue repair and demonstrated that sericin has neurotrophic and neuroprotective functions and prevents hypoxia and low glucose-induced cortical neuron death by modulation of the Bcl-2/BAX protein ratio and promotes the growth of primary neurons. In an in vitro study silk fibroin hydrolysate has been shown to protect neuronal cells against hydrogen peroxide $\left(\mathrm{H}_{2} \mathrm{O}_{2}\right)$ induced neurotoxicity by increased cell viability, which was attributed to its aromatic amino acids contents such as tyrosine and phenylalanine (Yeo et al., 2006). Moreover, silk fibroin has been proposed as an appropriate biomaterial for neural tissue engineering in the peripheral and central nervous system (CNS) therapies due to its good neurobiocompatibility. An in vitro study showed that administration of silk fibroin fiber to the cultured rat dorsal root ganglia (DRG) supports cell outgrowth from DRG and silk fibroin extract fluid improves survival of Schwann cells from rat sciatic nerves with no remarkable cytotoxicity (Yang et al., 2007a). Three-dimensional (3D) silk fibroin with uniaxial multichannels directs the axonal adhesion and elongation of primary hippocampal neurons (Zhang et al., 2012). Furthermore, silk fibroin-based nerve graft has been shown to promote peripheral nerve regeneration in a rat model of sciatic nerve injury (Yang et al., 2007b). Tang et al. have also demonstrated that silk fibroin fibers promote the survival and growth of rat hippocampal neurons and administration of silk fibroin extract into the cell culture medium exerts no cytotoxic effects on the hippocampal neurons phenotype or functions (Tang et al., 2009). The tolerability of the implantation of silk fibroin hydrogels into the mice striatum has also been reported without inducing cell death or cognitive and sensorimotor deficits (Fernández-García et al., 2016). It has been demonstrated that electrospun silk fibroin nanofibers promote the growth and expansion of the Schwann cells, suggesting that silk fibroin can promote the regeneration of axons following axotomy and nerve-crush traumas (Hu et al., 2012). Moreover, in an in vitro model of traumatic optic neuropathy, electrospun silk fibers loaded with growth factor were reported to promote survival and neurite outgrowth of the retinal ganglion cells (Wittmer et al., 2011). A recent in vivo study has also shown that topical sericin combined with swimming exercise improved sciatic nerve injury in Wistar rats (Debastiani et al., 2019).

\section{Conclusions}

Based on above, silk proteins play an effective role in the improvement of the brain function and provide protection against many neurodegenrative disorders. Moreover, silk proteins have biocompatibility, easy availability, and negligible immunogenicity, which make them a cost-effective and promising biomaterial in neuroregenerative medicine with vast potential (Fig. 1). Therefore, silk proteins can be a useful complementary strategy for physiological protection and functional recovery of the central and peripheral nervous system. Despite the long-established application of silk proteins as biomaterials and scaffolds, more in vivo studies are needed to verify the full neuroactive potentials of silk proteins. The fundamental and applied research will further elaborate the application of silk proteins in the neuroscience.

\section{Conflict of interest}

The authors have no conflict of interests to declare.

\section{Acknowledgement}

This study was financially supported by a grant from Vice-Chancellor for Research of Tabriz University of Medical Sciences, Tabriz, Iran (Grant No. 59935).

\section{References}

Ahsan F, Ansari TM, Usmani S, Bagga P (2018). An insight on silk protein sericin: from processing to biomedical application. Drug Res (Stuttg) 68(6): 317-327. DOI: 10.1055/s-0043-121464.

Alagiakrishnan K, Sankaralingam S, Ghosh M, Mereu L, Senior P (2013). Antidiabetic drugs and their potential role in treating mild cognitive impairment and Alzheimer's disease. Discov Med 16(90) 277-286. 
Ali MM, Arumugam SB (2011). Effect of crude extract of Bombyx mori coccoons in hyperlipidemia and atherosclerosis. J Ayurveda Integr Med 2(2): 72-78. DOI: 10.4103/0975-9476.82527.

Aramwit P, Sangcakul A (2007). The effects of sericin cream on wound healing in rats. Biosci Biotechnol Biochem 71(10): 24732477. DOI: $10.1271 / \mathrm{bbb} .70243$.

Aramwit P, Damrongsakkul S, Kanokpanont S, Srichana T (2010a). Properties and antityrosinase activity of sericin from various extraction methods. Biotechnol Appl Biochem 55(2): 91-98. DOI: 10.1042/BA20090186.

Aramwit P, Ekasit S, Yamdech R (2015). The development of nontoxic ionic-crosslinked chitosan-based microspheres as carriers for the controlled release of silk sericin. Biomed Microdevices 17(5): 84. DOI: 10.1007/s10544-015-9991-4.

Aramwit P, Kanokpanont S, De-Eknamkul W, Srichana T (2009). Monitoring of inflammatory mediators induced by silk sericin. J Biosci Bioeng 107(5): 556-561. DOI: 10.1016/j. jbiosc.2008.12.012.

Aramwit P, Kanokpanont S, Nakpheng T, Srichana T (2010b). The effect of sericin from various extraction methods on cell viability and collagen production. Int J Mol Sci 11(5): 2200-2211. DOI: $10.3390 /$ ijms11052200.

Aramwit P, Siritientong T, Srichana T (2012). Potential applications of silk sericin, a natural protein from textile industry by-products. Waste Manag Res 30(3): 217-224. DOI: 10.1177/0734242X11404733.

Arborelius L, Owens MJ, Plotsky PM, Nemeroff CB (1999). The role of corticotropin-releasing factor in depression and anxiety disorders. J Endocrinol 160(1): 1-12.

Asanuma M, Miyazaki I, Ogawa N (2003). Dopamine-or L-DOPAinduced neurotoxicity: the role of dopamine quinone formation and tyrosinase in a model of Parkinson's disease. Neurotox Res 5(3): 165-176.

Banagozar Mohammadi A, Torbati M, Farajdokht F, SadighEteghad S, Fazljou SM, Vatandoust SM, et al. (2019). Sericin alleviates restraint stress induced depressive-and anxiety-like behaviors via modulation of oxidative stress, neuroinflammation and apoptosis in the prefrontal cortex and hippocampus. Brain Res 1715: 47-56. DOI: 10.1016/j.brainres.2019.03.020.

Brieger K, Schiavone S, Miller FJ Jr., Krause KH (2012). Reactive oxygen species: from health to disease. Swiss Med Wkly 142: w13659. DOI: 10.4414/smw.2012.13659.

Cao TT, Zhang YQ (2016). Processing and characterization of silk sericin from Bombyx mori and its application in biomaterials and biomedicines. Mater Sci Eng C Mater Biol Appl 61: 940-952. DOI: 10.1016/j.msec.2015.12.082.

Cardona-Gómez GP, Mendez P, Doncarlos LL, Azcoitia I, GarciaSegura LM (2001). Interactions of estrogens and insulin-like growth factor-I in the brain: implications for neuroprotection. Brain Res Rev 37(1-3): 320-334. DOI: 10.1016/S01650173(01)00137-0.

Celedón JC, Palmer LJ, Xu X, Wang B, Fang Z, Weiss ST (2001). Sensitization to silk and childhood asthma in rural China. Pediatrics 107(5): e80-e80. DOI: 10.1542/peds.107.5.e80.

Cha Y, Lee SH, Jang SK, Guo H, Ban YH, Park D, et al. (2017). A silk peptide fraction restores cognitive function in AF64A-induced Alzheimer disease model rats by increasing expression of choline acetyltransferase gene. Toxicol Appl Pharmacol 314: 48-54. DOI: 10.1016/j.taap.2016.11.008.

Chae HS, Kang YK, Shin YK, Lee HJ, Yu JI, Lee KG, et al. (2004). The role of BF-7 on neuroprotection and enhancement of cognitive function. Korean J Physiol Pharmacol 8(4): 173-179.

Chen Z, He Y, Song C, Dong Z, Su Z, Xue J (2012). Sericin can reduce hippocampal neuronal apoptosis by activating the Akt signal transduction pathway in a rat model of diabetes mellitus. Neural Regen Res 7(3): 197-201. DOI: 10.3969/j.issn.16735374.2012.03.007.

Chen Z, Yang S, He Y, Song C, Liu Y (2013). Effect of sericin on diabetic hippocampal growth hormone/insulin-like growth factor 1 axis. Neural Regen Res 8(19): 1756-1764. DOI: 10.3969/j. issn.1673-5374.2013.19.003.
Chen ZH, Yang SH, Chen C (2011). Effects of sericin on nitric oxide content and nitric oxide synthase expression in hippocampus of diabetes mellitus rats. Chin J Gerontol 9: 034.

Chiarelli F, Giannini C, Mohn A (2004). Growth, growth factors and diabetes. Eur J Endocrinol 151(Suppl. 3): U109-U117.

Chlapanidas T, Faragò S, Lucconi G, Perteghella S, Galuzzi M, Mantelli M, et al. (2013). Sericins exhibit ROS-scavenging, anti-tyrosinase, anti-elastase, and in vitro immunomodulatory activities. Int J Biol Macromol 58: 47-56. DOI: 10.1016/j. ijbiomac.2013.03.054.

Choi GH, Jo MN, Moon SH, Lim SM, Jung AR, Yoon YC, Paik HD (2008). Neuroprotective effects and physicochemical characteristics of milk fortified with fibroin BF-7. Korean J Food Sci An Food Sci 28(4): 431-436. DOI: 10.5851/ kosfa.2008.28.4.431.

Cobley JN, Fiorello ML, Bailey DM (2018). 13 reasons why the brain is susceptible to oxidative stress. Redox Biol 15: 490-503. DOI: 10.1016/j.redox.2018.01.008.

Dash R, Acharya C, Bindu PC, Kundu SC (2008). Antioxidant potential of silk protein sericin against hydrogen peroxide-induced oxidative stress in skin fibroblasts. BMB Rep 41(3): 236-241. DOI: 10.5483/bmbrep.2008.41.3.236.

Debastiani JC, Santana AJ, Ribeiro LF, Brancalhão RM, Bertolini GR (2019). Sericin silk protein in peripheral nervous repair associated with the physical exercise of swimming in Wistar rats. Neurol Res 41(4): 326-334. DOI: 10.1080/01616412.2018.1564187.

Deori M, Devi D, Kumari S, Hazarika A, Kalita H, Sarma R, Devi R (2016). Antioxidant effect of sericin in brain and peripheral tissues of oxidative stress induced hypercholesterolemic rats. Front Pharmacol 7: 319. DOI: 10.3389/fphar.2016.00319.

Do SG, Park JH, Nam H, Kim JB, Lee JY, Oh YS., Suh JG (2012). Silk fibroin hydrolysate exerts an anti-diabetic effect by increasing pancreatic $\beta$ cell mass in C57BL/KsJ-db/db mice. J Vet Sci 13(4): 339-344. DOI: 10.4142/jvs.2012.13.4.339.

El-Mir MY, Detaille D, Gloria R, Delgado-Esteban M, Guigas B, Attia S, et al. (2008). Neuroprotective role of antidiabetic drug metformin against apoptotic cell death in primary cortical neurons. J Mol Neurosci 34(1): 77-87. DOI: 10.1007/s12031-0079002-1.

Feldman HA, Longcope C, Derby CA, Johannes CB, Araujo AB, Coviello AD (2002). Age trends in the level of serum testosterone and other hormones in middle-aged men: longitudinal results from the Massachusetts male aging study. J Clin Endocrinol Metab 87(2): 589-598. DOI: 10.1210/jcem.87.2.8201.

Fernández-García L, Marí-Buyé N, Barios JA, Madurga R, Elices M, Pérez-Rigueiro J, et al. (2016). Safety and tolerability of silk fibroin hydrogels implanted into the mouse brain. Acta biomaterialia 45: 262-275. DOI: 10.1016/j.actbio.2016.09.003.

Florczak A, Mackiewicz A, Dams-Kozlowska H (2014). Functionalized spider silk spheres as drug carriers for targeted cancer therapy. Biomacromolecules 15(8): 2971-2981. DOI: $10.1021 / \mathrm{bm} 500591 \mathrm{p}$.

Fridovich I (1986). Biological effects of the superoxide radical. Arch Biochem Biophys 247(1): 1-11. DOI: 10.1016/00039861(86)90526-6.

Goyal S, Siddiqui MK, Siddiqui KM, Arora S, Mittal R, Joshi S, Arya DS (2010). Cardioprotective effect of 'Khamira Abresham Hakim Arshad Wala' a unani formulation in isoproterenol-induced myocardial necrosis in rats. Exp Toxicol Pathol 62(1): 61-74. DOI: 10.1016/j.etp.2009.02.115.

Greggio E, Bergantino E, Carter D, Ahmad R, Costin GE, Hearing VJ, et al. (2005). Tyrosinase exacerbates dopamine toxicity but is not genetically associated with Parkinson's disease. J Neurochem 93(1): 246-256. DOI: 10.1111/j.1471-4159.2005.03019.x.

Gupta D, Agrawal A, Chaudhary H, Gulrajani M, Gupta C (2013). Cleaner process for extraction of sericin using infrared. J Clean Prod 52: 488-494. DOI: 10.1016/j.jclepro.2013.03.016.

Gurgo RD, Bedi KS, Nurcombe V (2002). Current concepts in central nervous system regeneration. J Clin Neurosci 9(6): 613-617. DOI: 10.1054/jocn.2002.1080.

Haapakoski R, Mathieu J, Ebmeier KP, Alenius H, Kivimäki M (2015). Cumulative meta-analysis of interleukins 6 and $1 \beta$, 
tumour necrosis factor $\alpha$ and C-reactive protein in patients with major depressive disorder. Brain Behav Immun 49: 206-215. DOI: 10.1016/j.bbi.2015.06.001.

Halliwell B, Gutteridge JM (2015). Free radicals in biology and medicine. Oxford: Oxford University Press.

Hameed A (1983). Avicenna's Tract on cardiac drugs and essays on Arab cardiotherapy. Hamdard Foundation Press.

Hasegawa T, Treis A, Patenge N, Fiesel FC, Springer W, Kahle PJ (2008). Parkin protects against tyrosinase-mediated dopamine neurotoxicity by suppressing stress-activated protein kinase pathways. J Neurochem 105(5): 1700-1715. DOI: 10.1111/j.14714159.2008.05277.x.

He YQ, Fu WL, Ma HW (2011). Effects of sericine on HO-1 expression in hippocampus of type 2 diabetic rats. J China Med Univ 4: 006.

Hopkins AM, De Laporte L, Tortelli F, Spedden E, Staii C, Atherton TJ, et al. (2013). Silk hydrogels as soft substrates for neural tissue engineering. Adv Funct Mater 23(41): 5140-5149. DOI: $10.1002 / \mathrm{adfm} .201300435$.

Hu A, Zuo B, Zhang F, Lan Q, Zhang H (2012). Electrospun silk fibroin nanofibers promote Schwann cell adhesion, growth and proliferation. Neural Regen Res 7(15): 1171-1178. DOI: $10.3969 /$ j.issn.1673-5374.2012.15.008.

Huang W, Ling S, Li C, Omenetto FG, Kaplan DL (2018). Silkworm silk-based materials and devices generated using bionanotechnology. Chem Soc Rev 47(17): 6486-6504.

Hulbert A, Pamplona R, Buffenstein R, Buttemer W (2007). Life and death: metabolic rate, membrane composition, and life span of animals. Physiol Rev 87(4): 1175-1213. DOI: 10.1152/ physrev.00047.2006.

Hureau C, Faller P (2009). A $\beta$-mediated ROS production by $\mathrm{Cu}$ ions: structural insights, mechanisms and relevance to Alzheimer's disease. Biochimie 91(10): 1212-1217. DOI: 10.1016/j. biochi.2009.03.013.

Iborra FJ, Kimura H, Cook PR (2004). The functional organization of mitochondrial genomes in human cells. BMC Biology 2: 9. DOI: 10.1186/1741-7007-2-9.

Ishihara M, Mochizuki-Oda N, Iwatsuki K, Kishima H, Iwamoto Y, Ohnishi YI, et al. (2011). A new three-dimensional axonal outgrowth assay for central nervous system regeneration. J Neurosci Methods 198(2): 181-186. DOI: 10.1016/j. jneumeth.2011.03.020.

Jung EY, Lee HS, Lee HJ, Kim JM, Lee KW, Suh HJ (2010). Feeding silk protein hydrolysates to $\mathrm{C} 57 \mathrm{BL} / \mathrm{KsJ}-\mathrm{db} / \mathrm{db}$ mice improves blood glucose and lipid profiles. Nutr Res 30(11): 783-790. DOI: 10.1016/j.nutres.2010.10.006.

Juurlink BH, Sweeney MI (1997). Mechanisms that result in damage during and following cerebral ischemia. Neurosci Biobehav Rev 21(2): 121-128. DOI: 10.1016/S0149-7634(96)00001-2.

Kang YK, Lee BY, Bucci LR, Stohs SJ (2018). Effect of a fibroin enzymatic hydrolysate on memory improvement: a placebocontrolled, double-blind study. Nutrients 10(2): 233. DOI: $10.3390 / \mathrm{nu} 10020233$.

Kang YK, Nam SH, Sohn HO, Lee DW (2005). Inhibitory effect of silkworm-extract (se) on monoamine oxidase activity in vitro and in vivo. Entomol Res 35(3): 189-193. DOI: 10.1111/j.17485967.2005.tb00158.x.

Kang YK, Oh HS, Cho YH, Kim YJ, Han YG, Nam SH (2010). Effects of a silkworm extract on dopamine and monoamine oxidase- $B$ activity in an MPTP-induced Parkinsons disease model. Lab Anim Res 26(3): 287-292. DOI: 10.5625/lar.2010.26.3.287.

Kato N, Sato S, Yamanaka A, Yamada H, Fuwa N, Nomura M (1998a). Silk protein, sericin, inhibits lipid peroxidation and tyrosinase activity. Biosci Biotechnol Biochem 62(1): 145-147. DOI: 10.1271/bbb.62.145.

Kato N, Sato S, Yamanaka A, Yamada H, Fuwa N, Nomura M (1998b). Silk protein, sericin, inhibits lipid peroxidation and tyrosinase activity. Biosci Biotechnol Biochem 62(1): 145-147. DOI: 10.1271/bbb.62.145.

Keawkorn W, Limpeanchob N, Tiyaboonchai W, Pongcharoen S, Sutheerawattananonda M (2012). Effects of silk sericin on the proliferation and apoptosis of colon cancer cells. Biol Res 45(1): 45-50. DOI: 10.4067/S0716-97602012000100006.
Keawkorn W, Limpeanchob N, Tiyaboonchai W, Pongcharoen S, Sutheerawattananonda M (2013). The effect of dietary sericin on rats. Science Asia 39: 252-256. DOI: 10.2306/ scienceasia1513-1874.2013.39.252.

Khan MS, Singh M, Khan MA, Arya D, Ahmad S (2014). Scientific validation of cardioprotective attribute by standardized extract of Bombyx mori against doxorubicin-induced cardiotoxicity in murine model. EXCLI J 13: 1043-1054.

Kim DH, Kim OH, Yeo JH, Lee KG, Park GD, Kim DJ, et al. (2010a). The improvement of short-and long-term memory of young children by BF-7. Korean J Food Sci An Food Sci 39(3): 376-382. DOI: 10.3746/jkfn.2010.39.3.376.

Kim HS, Seong JH, Lee YG, Xie CL, Shin JM, Yoon HD (2010b). Improvements caused by silk sericin extract derived from silkworm in blood glucose and lipid concentration in diabetic rats. Korean J Food Nutr 23: 392-398.

Kim DK, Kang YK, Lee MY, Lee KG, Yeo JH, Lee WB, et al. (2005). Neuroprotection and enhancement of learning and memory by BF-7. J Health Sci 51(3): 317-324. DOI: 10.1248/jhs.51.317.

Kim E, Sohn S, Lee M, Jung J, Kineman R, Park S (2006). Differential responses of the growth hormone axis in two rat models of streptozotocin-induced insulinopenic diabetes. J Endocrinol 188(2): 263-270. DOI: 10.1677/joe.1.06501.

Kim GH, Kim JE, Rhie SJ, Yoon S (2015). The role of oxidative stress in neurodegenerative diseases. Exp Neurobiol 24(4): 325-340. DOI: 10.5607/en.2015.24.4.325.

Kim K, Park S, Yoo HK, Lee JY, Jung HY, Kim DH, et al. (2009). Brain factor-7 extracted from Bombyx mori enhances cognition and attention in normal children. J Med Food 12(3): 643-648. DOI: 10.1089/jmf.2008.1236.

Kim SS, Kang YK, Park CH, Lee SH, Joo WS, Lee WB, et al. (2011a). Silk peptide for improving neuroprotective and neurofunctional effects and a method of its preparation. [online] [cit. 201907-09]. Available from: https://patents.google.com/patent/ WO2006014033A1

Kim TK, Park D, Yeon S, Lee SH, Choi YJ, Bae DK, et al. (2011b). Tyrosine-fortified silk amino acids improve physical function of Parkinson's disease rats. Food Sci Biotechnol 20(1): 79-84.

Kumar JP, Mandal BB (2017). Antioxidant potential of mulberry and non-mulberry silk sericin and its implications in biomedicine. Free Radic Biol Med 108: 803-818. DOI: 10.1016/j. freeradbiomed.2017.05.002.

Kunz RI, Brancalhão RM, Ribeiro LD, Natali MR (2016). Silkworm sericin: Properties and biomedical applications. BioMed Res Int 2016: ID 8175701. DOI: 10.1155/2016/8175701.

Kurland NE, Ragland RB, Zhang A, Moustafa ME, Kundu SC, Yadavalli VK (2014). pH responsive poly amino-acid hydrogels formed via silk sericin templating. Int J Biol Macromol 70: 565-571. DOI: 10.1016/j.ijbiomac.2014.07.036.

Lamboni L, Gauthier M, Yang G, Wang Q (2015). Silk sericin: A versatile material for tissue engineering and drug delivery. Biotechnol Adv 33(8): 1855-1867. DOI: 10.1016/j. biotechadv.2015.10.014.

Larin N (1951). Preparation of the specific purified antigen of canine hepatitis virus and antiserum for serological studies. Nature 168(4278): 745-746. DOI: 10.1038/168745b0.

Lee DY, Yun JY, Kim JI, Kim DH, Han IS Lee WB (2007). Protective effect of fibroin BF-7 on neuronal cell death in alzheimer model using amyloid beta peptide. Korean J Anat 40: 57-67.

Lee JY, Lee SH, Sung JJ, Kim ET, Cho HJ, Kim KH, et al. (2005). The effect of BF-7 on the ischemia-induced learning and memory deficits. Korean J Anat 38: 181-188.

Lee MY, Lee SH, Lee JS, Min KJ, Lee KG, Yeo JH, et al. (2004). BF-7 improved memory function and protected neuron from oxidative stress. Korean J Phys Anthropol 17(4): 313-320. DOI: 10.11637/ kjpa.2004.17.4.313.

Leker RR, Shohami E (2002). Cerebral ischemia and trauma different etiologies yet similar mechanisms: neuroprotective opportunities. Brain Res Rev 39(1): 55-73. DOI: 10.1016/S01650173(02)00157-1.

Li Q, Yan Y, Qiao Z, Chen Z (2012). Changes of NO content in hippocampus of diabetes mellitus rats and protective effects of sericin. Journal of Chengde Medical College 3: 004. 
Li ZH, Ji SC, Wang YZ, Shen XC, Liang H (2013). Silk fibroin-based scaffolds for tissue engineering. Front Mater Sci 7(3): 237-247.

Liang CC, Park AY, Guan JL (2007). In vitro scratch assay: a convenient and inexpensive method for analysis of cell migration in vitro. Nat Protoc 2(2): 329-333.DOI: 10.1038/nprot.2007.30.

Maes M, Galecki P, Chang YS, Berk M (2011). A review on the oxidative and nitrosative stress (O\&NS) pathways in major depression and their possible contribution to the (neuro)degenerative processes in that illness. Prog Neuropsychopharmacol Biol Psychiatry 35(3): 676-692. DOI: 10.1016/j.pnpbp.2010.05.004.

Maes M, Mihaylova I, Kubera M, Uytterhoeven M, Vrydags N, Bosmans E (2009a). Coenzyme Q10 deficiency in myalgic encephalomyelitis/chronic fatigue syndrome (ME/CFS) is related to fatigue, autonomic and neurocognitive symptoms and is another risk factor explaining the early mortality in ME/CFS due to cardiovascular disorder. Neuro Endocrinol Lett 30(4): 470-476.

Maes M, Mihaylova I, Kubera M, Uytterhoeven M, Vrydags N, Bosmans E (2009b). Lower plasma Coenzyme Q 10 in depression: a marker for treatment resistance and chronic fatigue in depression and a risk factor to cardiovascular disorder in that illness. Neuroendocrinol Lett 30(4): 462-469.

Mijnhout GS, Scheltens P, Diamant M, Biessels GJ, Wessels AM, Simsek S, et al. (2006). Diabetic encephalopathy: A concept in need of a definition. Diabetologia 49(6): 1447-1448. DOI: 10.1007/s00125-006-0221-8.

Mondal M (2007). The silk proteins, sericin and fibroin in silkworm, Bombyx mori Linn.,-a review. Caspian J Environmen Sci 5(2): 63-76.

Moore DJ, West AB, Dawson VL, Dawson TM (2005). Molecular pathophysiology of Parkinson's disease. Annu Rev Neurosci 28: 57-87. DOI: 10.1146/annurev.neuro.28.061604.135718.

Nazmi AS, Ahmad SJ, Rashikh A, Akhtar M, Pillai KK, Najmi AK (2011). Protective effects of 'Khamira Abresham Hakim Arshad Wala', a unani formulation against doxorubicin-induced cardiotoxicity and nephrotoxicity. Toxicol Mech Methods 21(1): 41-47. DOI: 10.3109/15376516.2010.529188.

Okazaki Y, Kakehi S, Xu Y, Tsujimoto K, Sasaki M, Ogawa H, Kato N (2010). Consumption of sericin reduces serum lipids, ameliorates glucose tolerance and elevates serum adiponectin in rats fed a high-fat diet. Biosci Biotechnol Biochem 74(8): 1534-1538. DOI: 10.1271/bbb.100065.

Onsa-Ard A, Shimbhu D, Tocharus J, Sutheerawattananonda M, Pantan R, Tocharus C (2013). Hypotensive and vasorelaxant effects of sericin-derived oligopeptides in rats. ISRN Pharmacol 2013: ID: 717529.

Oshika M, Naito S (1998). Acylated silk proteins for hair care. [online] [cit. 2019-07-09]. Available from: https://patents.google. com/patent/US5747015

Padamwar M, Pawar A (2004). Silk sericin and its applications: A review. J Sci Ind Res 63(4): 323-329.

Panico A, Paladini F, Pollini M (2018). Development of regenerative and flexible fibroin-based wound dressings. J Biomed Mater Res B Appl Biomater 107(1): 7-18. DOI: 10.1002/jbm.b.34090.

Panilaitis B, Altman GH, Chen J, Jin HJ, Karageorgiou V, Kaplan DL (2003). Macrophage responses to silk. Biomaterials 24(18): 3079-3085. DOI: 10.1016/S0142-9612(03)00158-3.

Park D, Lee SH, Choi YJ, Bae D-K, Yang Y-H, Yang G, et al. (2011). Improving effect of silk peptides on the cognitive function of rats with aging brain facilitated by D-galactose. Korean Soci Appl Pharmacol 19(2): 224-230.

Patrone C, Eriksson O, Lindholm D (2014). Diabetes drugs and neurological disorders: new views and therapeutic possibilities. Lancet Diabetes Endocrinol 2(3): 256-262. DOI: 10.1016/S22138587(13)70125-6.

Peera K, Yellamma K (2013). Silk protein, sericin effect on morphometric and behavioural aspects in alzheimers disease induced rat model. J Pharm Res 2: 1-5.

Peera K, Yellamma K (2015). Sericin as a chlinergic modulator in alzaeimer's disease induced rat. Int J Pharm Pharm Sci 7: 108-112.
Peera K, Yellamma K (2016). Evaluation of potential antioxidant activity of silk protein - sericin against Alzheimer's disease induced rat brain. Science Spectrum 1: 384-395.

Preda RC, Leisk G, Omenetto F, Kaplan DL (2013). Bioengineered silk proteins to control cell and tissue functions. Methods Mol Biol 996: 19-41. DOI: 10.1007/978-1-62703-354-1_2.

Promphet P, Bunarsa S, Sutheerawattananonda M, Kunthalert D (2014). Immune enhancement activities of silk lutein extract from Bombyx mori cocoons. Biol Res 47(1): 15. DOI: 10.1186/07176287-47-15.

Qi Y, Wang H, Wei K, Yang Y, Zheng RY, Kim I, Zhang KQ (2017). A review of structure construction of silk fibroin biomaterials from single structures to multi-level structures. Int J Mol Sci 18(3): 237. DOI: $10.3390 / \mathrm{ijms} 18030237$.

Rattana S, Katisart T, Butiman C, Sungthong B (2017). Antihyperglycemic effect of silkworm powder, fibroin and sericin from three thai silkworm (Bombyx mori Linn.) in streptozotocininduced diabetic rats. Pharmacogn J 9(4): 559-564. DOI: 10.5530/ pj.2017.4.89.

Sadigh-Eteghad S, Majdi A, Mccann SK, Mahmoudi J, Vafaee MS, Macleod MR (2017). D-galactose-induced brain ageing model: A systematic review and meta-analysis on cognitive outcomes and oxidative stress indices. PloS One 12(8): e0184122-e0184122. DOI: 10.1371/journal.pone.0184122.

Salehpour F, Farajdokht F, Cassano P, Sadigh-Eteghad S, Erfani M, Hamblin MR, et al. (2019). Near-infrared photobiomodulation combined with coenzyme Q10 for depression in a mouse model of restraint stress: reduction in oxidative stress, neuroinflammation, and apoptosis. Brain Res Bul 144: 213-222. DOI: 10.1016/j. brainresbull.2018.10.010.

Salim S (2017). Oxidative stress and the central nervous system. J Pharmacol Exp Ther 360(1): 201-205. DOI: 10.1124/ jpet.116.237503.

Sánchez-Ferrer A, Rodríguez-López JN, García-Cánovas F, García-Carmona F (1995). Tyrosinase: a comprehensive review of its mechanism. Biochim Biophys Acta 1247(1): 1-11. DOI: 10.1016/0167-4838(94)00204-t.

Sasaki M, Kato N, Watanabe H, Yamada H (2000). Silk protein, sericin, suppresses colon carcinogenesis induced by 1 , 2-dimethylhydrazine in mice. Oncol Rep 7(5): 1049-1101. DOI: 10.3892/or.7.5.1049.

Seo CW, Um IC, Rico CW, Kang MY (2011). Antihyperlipidemic and body fat-lowering effects of silk proteins with different fibroin/ sericin compositions in mice fed with high fat diet. J Agric Food Chem 59(8): 4192-4197. DOI: 10.1021/jf104812g.

Shangguan F, Shi J (2007). Effect of growth hormone/IGF-1 on cognitive function. Zhongguo Xinli Weisheng Zazhi 21: 568-570.

Shichiri M (2014). The role of lipid peroxidation in neurological disorders. J Clin Biochem Nutr 54(3): 151-160. DOI: 10.3164/ jcbn.14-10.

Sina I (1995). Risala Advia Qalbiya (Persian Translation). Aligarh, India: AMU.

Song C, Yang Z, Zhong M, Chen Z (2013). Sericin protects against diabetes-induced injuries in sciatic nerve and related nerve cells. Neural Regen Res 8(6): 506-513. DOI: 10.3969/j.issn.16735374.2013.06.003.

Srivastav RK, Siddiqui HH, Mahmood T, Ahsan F (2013). Evaluation of cardioprotective effect of silk cocoon (Abresham) on isoprenaline-induced myocardial infarction in rats. Avicenna J Phytomed 3(3): 216-223.

Tamada Y, Sano M, Niwa K, Imai T, Yoshino G (2004). Sulfation of silk sericin and anticoagulant activity of sulfated sericin. J Biomater Sci Polym Ed 15(8): 971-980.

Tang X, Ding F, Yang Y, Hu N, Wu H, Gu X (2009). Evaluation on in vitro biocompatibility of silk fibroin-based biomaterials with primarily cultured hippocampal neurons. J Biomed Mater Res A 91(1): 166-174. DOI: 10.1002/jbm.a.32212.

Tangvarasittichai $S$ (2015). Oxidative stress, insulin resistance, dyslipidemia and type 2 diabetes mellitus. World J Diabetes 6(3): 456-480. DOI: 10.4239/wjd.v6.i3.456.

Terada S, Sasaki M, Yanagihara K, Yamada H (2005). Preparation of silk protein sericin as mitogenic factor for better mammalian 
cell culture. J Biosci Bioeng 100(6): 667-671. DOI: 10.1263/ jbb.100.667.

Verdile G, Fuller SJ, Martins RN (2015). The role of type 2 diabetes in neurodegeneration. Neurobiol Dis 84: 22-38. DOI: $10.1016 / j$. nbd.2015.04.008.

Walsh TJ, Opello KD (1994). The Use of AF64A (Ethylcholine Aziridinium Ion) to Model Alzheimer's Disease. Toxin-induced models of neurological disorders In: Woodruff ML, Nonneman AJ (Eds). Toxin-induced models of neurological disorders. Boston, MA: Springer.

Wang Z, Wang J, Jin Y, Luo Z, Yang W, Xie H, et al. (2015). A neuroprotective sericin hydrogel as an effective neuronal cell carrier for the repair of ischemic stroke. ACS Appl Mater Interfaces 7(44): 24629-24640. DOI: 10.1021/acsami.5b06804.

Wine RN, Mcpherson CA, Harry GJ (2009). IGF-1 and pAKT signaling promote hippocampal CA1 neuronal survival following injury to dentate granule cells. Neurotox Res 16(3): 280-292. DOI: 10.1007/s12640-009-9060-y.

Wittmer CR, Claudepierre T, Reber M, Wiedemann P, Garlick JA, Kaplan D, Egles C (2011). Multifunctionalized electrospun silk fibers promote axon regeneration in the central nervous system. Adv Funct Mater 21(22): 4232-4242. DOI: 10.1002/ adfm.201190103.

Wong J, Chan HK, Chrzanowski W (2014). Silk for pharmaceutical and cosmeceutical applications. In: Kundu S (Ed.). Silk biomaterials for tissue engineering and regenerative medicine. Elsevier.

Xiong S, Zhang X, Lu P, Wu Y, Wang Q, Sun H, et al. (2017). A Gelatin-sulfonated silk composite scaffold based on 3d printing technology enhances skin regeneration by stimulating epidermal growth and dermal neovascularization. Sci Rep 7(1): 4288. DOI: 10.1038/s41598-017-04149-y.

Xu Z, Chen S, Wang Y, Chen S, Yao W, Gao X (2018). Neuroprotective effects of silk fibroin hydrolysate against $A \beta 25-35$ induced cytotoxicity in SH-SY5Y cells and primary hippocampal neurons by regulating ROS inactivation of PP2A. J Funct Foods 45: 100-109. DOI: 10.1016/j.jff.2018.03.032.

Yang Y, Chen X, Ding F, Zhang P, Liu J, Gu X (2007a). Biocompatibility evaluation of silk fibroin with peripheral nerve tissues and cells in vitro. Biomaterials 28(9): 1643-1652. DOI: 10.1016/j.biomaterials.2006.12.004.

Yang Y, Ding F, Wu J, Hu W, Liu W, Liu J, Gu X (2007b). Development and evaluation of silk fibroin-based nerve grafts used for peripheral nerve regeneration. Biomaterials 28(36): 5526-5535. DOI: 10.1016/j.biomaterials.2007.09.001.
Yellamma K (2014). Silk protein, sericin as a cognitive enhancer in Alzheimer's disease. J Alzheimers Dis Parkinsonism 4: 163. DOI: 10.4172/2161-0460.1000163.

Yeo JH, Lee KG, Kweon HY, Woo SO, Han SM, Kim SS, Demura M (2006). Fractionation of a silk fibroin hydrolysate and its protective function of hydrogen peroxide toxicity. J Appl Polym Sci 102(1): 772-776. DOI: 10.1002/app.23740.

Youdim MB, Riederer PF (2004). A review of the mechanisms and role of monoamine oxidase inhibitors in Parkinson's disease. Neurology 63(7 Suppl. 2): S32-S35. DOI: 10.1212/wnl.63.7_ suppl_2.s32.

Youdim MB, Edmondson D, Tipton KF (2006). The therapeutic potential of monoamine oxidase inhibitors. Nat Rev Neurosci 7(4): 295-309. DOI: $10.1038 /$ nrn1883.

Zaoming W, Codina R, Fernandez-Caldas E, Lockey R (1996). Partial characterization of the silk allergens in mulberry silk extract. J Investig Allergol Clin Immunol 6(4): 237-241.

Zawia NH, Lahiri DK, Cardozo-Pelaez F (2009). Epigenetics, oxidative stress, and Alzheimer disease. Free Radic Biol Med 46(9): 1241-1249.

Zhang J, Kaur J, Rajkhowa R, Li JL, Liu XY, Wang XG (2013). Mechanical properties and structure of silkworm cocoons: a comparative study of Bombyx mori, Antheraea assamensis, Antheraea pernyi and Antheraea mylitta silkworm cocoons. Mater Sci Eng C Mater Biol Appl 33(6): 3206-3213. DOI: 10.1016/j. msec.2013.03.051.

Zhang Q, Zhao Y, Yan S, Yang Y, Zhao H, Li M, et al. (2012). Preparation of uniaxial multichannel silk fibroin scaffolds for guiding primary neurons. Acta Biomater 8(7): 2628-2638. DOI: 10.1016/j.actbio.2012.03.033.

Zhang Y, Liu J, Huang L, Wang Z, Wang L (2015). Design and performance of a sericin-alginate interpenetrating network hydrogel for cell and drug delivery. Sci Rep 5: 12374. DOI: $10.1038 /$ srep12374.

Zhang Y, Zhao D, Meng Z, Dong Z, Lin Y, Chen S, et al. (2017). Wild silkworm cocoon contains more metabolites than domestic silkworm cocoon to improve its protection. J Insect Sci 17(5). DOI: 10.1093/jisesa/iex069.

Zhao XL, Zhang YH, Zhang FX (2012). Effects of sericine on nerve growth factor expressions in anterior horn cells of spinal cord and spinal ganglia cells. Chinese J Gerontol 17: 043.

Zhaorigetu S, Sasaki M, Watanabe H, Kato N (2001). Supplemental silk protein, sericin, suppresses colon tumorigenesis in 1 , 2-dimethylhydrazine-treated mice by reducing oxidative stress and cell proliferation. Biosci Biotechnol Biochem 65(10): 2181-2186. DOI: 10.1271/bbb.65.2181. 